\title{
AXONAL REGENERATION IN LAMPREY SPINAL CORD ${ }^{1}$
}

\author{
HSIANG SHU YIN ${ }^{2}$ AND MICHAEL E. SELZER
}

Department of Neurology, University of Pennsylvania School of Medicine, Philadelphia, Pennsylvania 19104

Received August 30, 1982; Revised December 3, 1982; Accepted December 7, 1982

\begin{abstract}
Spinal cords of sea lamprey larvae were transected at one of two levels: $(a)$ rostral, at the last gill, or $(b)$ caudal, at the cloaca. Following various recovery times, regeneration of the posteriorly projecting giant reticulospinal axons (RAs) was demonstrated by intra-axonal injection of horseradish peroxidase (HRP). Regeneration of axons of anteriorly projecting dorsal cells (DCs) and giant interneurons (GIs) was demonstrated by intrasomatic HRP injection into cells located just below the transection scar.

After 40 days of recovery, $55 \%$ of proximally transected RAs (rostral cut) regenerated at least as far as the center of the scar, whereas only $15 \%$ of distally transected RAs (caudal cut) did so. Maximum distance of regeneration was $5.3 \mathrm{~mm}$ beyond the scar for proximally transected RAs but only $38 \mathrm{u}$ for distally transected RAs. Proximally transected RAs also branched more profusely than distally transected ones. These data (when combined with others in the literature) suggest that the regenerative capacity of RAs may decrease with distance of axotomy from the cell body. Distance of regeneration and degree of branching of proximally transected RAs peaked between 40 and 100 days. Thereafter, there appeared to be a tendency toward neurite retraction.

Of axotomized GIs, $76 \%$ regenerated anteriorly at least as far as the center of a caudal transection scar (GIs are located only in the caudal part of the cord). The maximum distance of regeneration was $1.3 \mathrm{~mm}$ beyond the scar. Of DC axons, $56 \%$ regenerated anteriorly at least as far as the transection site. The maximum distance was $1.1 \mathrm{~mm}$ beyond the scar. DCs located just below a caudal transection regenerated at least as well as those located below a rostral transection. Axonal regeneration was also demonstrated for a few lateral cells, edge cells, and crossed caudally projecting interneurons.
\end{abstract}

The spinal cord of larval sea lamprey is a convenient model for the study of regeneration in vertebrate central nervous system. Using the isolated spinal cord preparation, axonal regeneration of individual identified neurons can be demonstrated both morphologically and electrophysiologically.

Larval sea lampreys recover swimming coordination almost completely after transection of their spinal cords (Rovainen, 1976; Selzer, 1978). This is accompanied by a limited regeneration of the giant reticulospinal axons (Hibbard, 1963; Rovainen, 1976; Selzer, 1978; Wood and Cohen, 1979; Borgens et al., 1981). The behavioral recovery is likely to be based on the spinal cord regeneration because (1) reflexive movements can be elicited across an isolated length of spinal cord which includes the transection scar (Selzer, 1978), and (2) retransection at

\footnotetext{
' This work was supported by National Institutes of Health Grants NS14837, NS14257, and RR05415. We wish to thank Dr. Marc Dichter for helpful comments on this manuscript.

${ }^{2}$ To whom correspondence should be addressed.
}

the level of the original lesion abolishes the recovery $(H$. S. Yin and M. E. Selzer, unpublished observation; Wood and Cohen, 1979).

Electrophysiological evidence for regeneration of axons in both rostral and caudal directions has been obtained by extracellular recordings (Selzer, 1978), and, in the case of caudally regenerating giant reticulospinal axons, by intracellular recordings (Borgens et al., 1981). Re-establishment of physiologically active polysynaptic connections has been demonstrated by intracellular recordings from giant interneurons (Selzer, 1978). Regeneration of individual giant reticulospinal axons has been demonstrated morphologically in unlabeled serial sections (Rovainen, 1976; Selzer, 1978) and by intracellular injection of horseradish peroxidase (HRP) or Lucifer Yellow (Wood and Cohen, 1979; Borgens et al., 1981).

In the present report, we have made intracellular injections of HRP not only into the posteriorly projecting giant reticulospinal axons (RAs, including Müller and Mauthner axons) but also into the anteriorly projecting giant interneurons (GIs) and dorsal cells (DCs) in order 
to further characterize and quantify regeneration patterns of transected lamprey spinal axons. Our findings suggest that all cell types examined thus far (including some types not studied systematically) have a limited capacity for axonal regeneration. They also suggest that RAs transected close to the cell body regenerate faster and further than those transected more distally. Finally, these studies show that regenerating axons do not continue to grow indefinitely but reach a peak distance at between 6 and 14 weeks; thereafter they seem to retract partially.

\section{Materials and Methods}

Surgery and dissection. Forty-one sea lamprey larvae (Petromyzon marinus), 9 to $13 \mathrm{~cm}$ long (approximately 4 to 5 years old), were anesthetized with $1 \%$ Tricaine methanesulfonate. Their spinal cords were transected either rostrally at the level of the last gill or caudally at the level of the cloaca. The completeness of the transection was assured by pushing apart slightly the two stumps of spinal cord to reveal the underlying notochord. The animals were then placed on ice for 2 to $3 \mathrm{hr}$, and the wound was allowed to air dry. They were then returned to an aerated aquarium for recovery at $23^{\circ} \mathrm{C}$. (A few were kept at $16^{\circ} \mathrm{C}$, but these did not show differences in regeneration from those at $23^{\circ} \mathrm{C}$ ). Five additional animals were used as unoperated controls.

Following various survival times, from 12 to 175 days, the animals were re-anesthetized and dissected in cold oxygenated lamprey solution ( $111 \mathrm{~mm} \mathrm{NaCl}, 2.1 \mathrm{~mm} \mathrm{KCl}$, $1.8 \mathrm{~mm} \mathrm{MgCl}_{2}, 10 \mathrm{mM}$ Tris buffer adjusted to a final $\mathrm{pH}$ of 7.4). Animals were eviscerated and their skin and muscle removed as described previously (Selzer, 1978). The notochord was split ventrally and pinned to the dissecting tray dorsal side up. The spinal cord was exposed by removal of the overlying spinal canal. The spinal cord tethered to the notochord was then transferred to a Sylgard-lined Plexiglas recording chamber filled with lamprey solution which was maintained at $10^{\circ} \mathrm{C}$ by a cooling sleeve.

Intracellular injection of horseradish peroxidase. Microelectrodes were pulled on a Brown-Flaming micropipette puller from thin walled $1 \mathrm{~mm}$ diameter omega dot micropipettes. Microelectrodes were filled with a $4 \%$ solution of HRP (Sigma IV) in $0.2 \mathrm{M} \mathrm{KCl}$ and $0.1 \mathrm{~m}$ Tris buffer, $\mathrm{pH}$ 7.4. Before use, their tips were beveled to resistances of 50 to 100 megohms.

Individual transilluminated neurons and axons were impaled under stereomicroscopic vision. A bipolar silversilver chloride stimulating electrode was placed either distal or proximal to the transection scar for antidromic and orthodromic activation of impaled neurons. Action potentials were elicited intracellularly by injection of depolarizing current through a bridge circuit and antidromically or orthodromically by stimulating the cord. (The electrophysiological responses of spinal neurons will be described in a subsequent paper.) The impaled neural elements were then injected iontophoretically with HRP by passing $3.3-\mathrm{Hz}, 200-\mathrm{msec}$ positive current pulses of 5 to $10 \mathrm{nA}$ for 10 to $15 \mathrm{~min}$ for DCs and GIs, 10 to $20 \mathrm{nA}$ for 20 to $30 \mathrm{~min}$ for RAs. Observations were made on HRP-injected axons and neurons away from the transec- tion zone or in unoperated control animals to determine the distance of axonal staining. Injection sites of axons and locations of neurons to be studied for regeneration were selected so as to be within these slaining ranges. Because there are only 12 to 25 GIs per spinal cord, we had to be less restrictive in selecting these cells. Thus, some of their regenerating axon tips were probably located beyond the staining range (see "Results").

Histological processing of HRP-injected neurons. After dye injection, the cord was kept in a refrigerator for $24 \mathrm{hr}$ to allow diffusion and/or transport of HRP. Subsequently, the cord was fixed in $2.5 \%$ glutaraldehyde in $0.1 \mathrm{M}$ phosphate buffer, $\mathrm{pH} 7.4$, for $2 \mathrm{hr}$ at $4^{\circ} \mathrm{C}$ and was then washed in phosphate buffer. The meninges were then stripped away as much as possible without damaging the cord. The specimen was incubated in $0.01 \%$ diaminobenzidine (DAB) in $0.1 \mathrm{M}$ phosphate buffer $(\mathrm{pH}$ 7.4) for $15 \mathrm{~min}$, after which $3 \% \mathrm{H}_{2} \mathrm{O}_{2}$ was added to the solution for another $15 \mathrm{~min}$. The tissue was incubated 15 min more in fresh $\mathrm{DAB} / \mathrm{H}_{2} \mathrm{O}_{2}$ solution. The developed tissue was washed in buffer or lamprey solution, dehydrated through serial ethanols, cleared in cedar wood oil for 20 to $30 \mathrm{~min}$, and mounted on a glass slide with Permount (Fisher).

Morphometric measurement of regeneration. The whole mounts were observed under the light microscope. The distance of neurite terminals from the midpoint of the scar and the diameters of parent axons were measured with a reticle eyepiece. The number of branches was determined for each axon. The branches which looped backward were also counted. The laterality of neurites in comparison to their parent axon was determined by the location of neurite terminals. Because of the flatness of the spinal cord and the disruption of normal architecture following transection, no attempt was made in the present study to specify the dorsoventral location of the axon tips.

\section{Results}

\section{General phenomena of axonal regeneration}

The area of transection was easily identified in whole mounts as a region of abrupt cord narrowing and disruption of the normal linear arrangement of axons. The large lucent profiles of unstained RAs disappeared at the rostral end of the scar. In addition, the central canal, which could be discerned in spinal segments above and below the scar by the refractile properties of its ependymal layer, widened and became less distinct within the scar. In the data listed below, the center of the scar, which could be localized to within $5 \mu$, was defined as $0 \mu$. Injected axons which terminated beyond or before the scar were assigned positive $(+)$ or negative $(-)$ distances. On an average, the scar was $500 \mu$ wide. Thus, neurites which terminated at distances 0 to $-250 \mu$ had actually regenerated into the scar; although for purposes of tabulation, only those ending at the center $(+5 \mu)$ were listed in Tables I and III as terminating within the scar.

For all the cell types during the first 20 days following transection, axon tip locations were proximal to the scar for varying distances up to about $2 \mathrm{~mm}$. This probably represents a minimum distance of retrograde degenera- 
TABLE I

Terminations of regenerating axon branches more than 40 days post-transection ${ }^{a}$

\begin{tabular}{lcccc}
\hline & \multicolumn{2}{c}{ Reticulospinal Axons } & Giant Inter- & $\begin{array}{c}\text { Dorsal } \\
\text { Cells }\end{array}$ \\
\cline { 2 - 3 } & $\begin{array}{c}\text { Rostral Tran- } \\
\text { section }\end{array}$ & $\begin{array}{c}\text { Caudal Tran- } \\
\text { section }\end{array}$ & & \\
\hline $\begin{array}{l}\text { Distal to scar } \\
\text { Branches }\end{array}$ & $44(44 \%)$ & $1(4 \%)$ & $8(67 \%)$ & $5(23 \%)$ \\
$\quad$ Axons & $26(49 \%)$ & $1(5 \%)$ & $5(63 \%)$ & $3(17 \%)$ \\
In scar & & & & \\
$\quad$ Branches & $13(13 \%)$ & $2(7 \%)$ & $1(8 \%)$ & $8(36 \%)$ \\
Axons & $3(6 \%)$ & $2(10 \%)$ & $1(13 \%)$ & $7(39 \%)$ \\
Proximal to scar & & & & \\
Branches & $44(44 \%)$ & $25(89 \%)$ & $3(25 \%)$ & $9(41 \%)$ \\
Axons & $24(45 \%)$ & $17(85 \%)$ & $2(25 \%)$ & $8(44 \%)$ \\
& & & & \\
Total & & & 12 & 22 \\
Branches & 101 & 28 & 8 & 18 \\
Axons & 53 & 20 & & \\
\hline
\end{tabular}

${ }^{a}$ For axons, the data represent the number in which at least one branch regenerated as far as indicated.

TABLE II

Paths of regenerating axon branches more than 40 days posttransection $^{a}$

\begin{tabular}{|c|c|c|c|c|}
\hline & \multicolumn{2}{|c|}{ Reticulospinal Axons } & \multirow{2}{*}{$\begin{array}{l}\text { Giant Inter- } \\
\text { neurons }\end{array}$} & \multirow{2}{*}{ Dorsal Cells } \\
\hline & $\begin{array}{l}\text { Rostral Tran- } \\
\text { section }\end{array}$ & $\begin{array}{l}\text { Caudal Tran- } \\
\text { section }\end{array}$ & & \\
\hline \multicolumn{5}{|c|}{$\begin{array}{l}\text { Contralateral to } \\
\text { pretransec- } \\
\text { tion }\end{array}$} \\
\hline Branches & $5(5 \%)$ & 0 & 0 & $1(5 \%)$ \\
\hline Axons & $4(8 \%)$ & 0 & 0 & $1(6 \%)$ \\
\hline \multicolumn{5}{|c|}{$\begin{array}{l}\text { Ipsilateral to } \\
\text { pretransec- } \\
\text { tion }\end{array}$} \\
\hline Branches & $96(95 \%)$ & $28(100 \%)$ & $12(100 \%)$ & $21(95 \%)$ \\
\hline Axons & $49(92 \%)$ & 20 (100\%) & $8(100 \%)$ & $17(94 \%)$ \\
\hline \multicolumn{5}{|c|}{$\begin{array}{l}\text { Looped back- } \\
\text { ward }\end{array}$} \\
\hline Branches & $11(11 \%)$ & $2(7 \%)$ & $3(25 \%)$ & $2(9 \%)$ \\
\hline Axons & $11(21 \%)$ & $2(10 \%)$ & $3(38 \%)$ & $2(11 \%)$ \\
\hline \multicolumn{5}{|l|}{ Total } \\
\hline Branches & 101 & 28 & 12 & 22 \\
\hline Axons & 53 & 20 & 8 & 18 \\
\hline
\end{tabular}

${ }^{a}$ The data on laterality refer to the locations of axon terminals. For axons, the data indicate the number in which at least one branch terminated in the indicated manner.

tion, because it is possible that some of these branches had already begun to elongate at the time of injection. The retrograde degeneration was followed by branching or elongation of the parent axons. The majority of branches grew toward the scar, i.e., in the normal direction of their original path. After 40 days, the majority of branches (except distally transected RAs) reached at least as far as the center of the scar (Table I). Some neurites looped back $180^{\circ}$, but they always stopped within $3.4 \mathrm{~mm}$ of the turn. Regenerating neurites narrowed and had curvilinear courses within the scar. However, before emerging from the scar they usually returned to the same side of the central canal as their parent axons (Table II) and resumed a straight path in the distal cord segment. When neurites filled by HRP showed profiles in the form of terminal enlargements (reminiscent of growth cones in peripheral nerves) or of blunted endings, we assumed that the tips were seen (Fig. $2 A$ ). However, some HRP profiles tapered or faded gradually. In these cases, we could not be certain that we were seeing the tip of the axon, and measured distances represented a lower limit estimate of regeneration length. Such profiles were noted in approximately $25 \%$ of RAs, $50 \%$ of GIs, and $60 \%$ of DCs. Therefore, the underestimation of average distance of regeneration may have been greater for GIs and DCs than for RAs.

\section{Reticulospinal axons}

RAs are large axons whose cell bodies are located in the brainstem. The largest of them are the approximately eight pairs of uncrossed Müller axons and a pair of crossed Mauthner axons. Both transections were too far from the brainstem for adequate movement of HRP from cell body to scar. Therefore, RAs were impaled directly near the transection and identified by their sizes, positions and electrical characteristics (Rovainen, 1967a) as either Mauthner axons or Müller-type axons, but not as axons of specific Müller cells (however, see below). The experimental arrangement is diagrammed in Figure 1. Eighty-three RAs (144 branches) were injected with HRP within $3 \mathrm{~mm}$ of the scar from 12 to 169 days posttransection (Fig. $2 A$ ). Of these, 60 (109 branches) were in animals with rostral transections and 23 ( 35 branches) were in animals with caudal transections. The time course of regeneration was plotted as the distances of neurite terminals from the center of the scar against the recovery times (Fig. $3, A$ and $B$ ). About $10 \%$ of regenerating neurites looped backward before terminating (Table II). For these cases, distance of regeneration was defined by the caudalmost reach of the loop. In 28 control HRP-injected RAs, the mean distance of visible staining away from the injection site was $6349 \mu \pm 361 \mathrm{SE}$. The longest distance was $9900 \mu$.

Rostral transections. For rostral transections, three axons injected at 12 days showed retrograde degeneration an average of $933 \mu \pm 431 \mathrm{SE}$. We do not know whether these tip locations reflected any axon elongation subsequent to their initial degeneration (Fig. $4 A$ ). By 39 days, they had reached $195 \mu \pm 81$ proximal to the scar. The peak of growth seemed to occur between 40 and 100 days, during which time the average neurite reached $574 \mu \pm$ 153 distal to the transection site. However, there was a great deal of variability. Individual neurites were traced as far as $5.3 \mathrm{~mm}$ beyond the scar. After 100 days, growth stopped and there seemed to be a significant $(p<0.05)$ retraction of neurites to $+77 \mu \pm 154$. This retraction process was also reflected in the average number of branches sprouting from each parent axon (Fig. $4 \mathrm{C}$ ). During the first 39 days post-transection, there was almost no branching of RAs. Between 40 and 60 days, RAs had 3.14 branches/axon $\pm 0.67 \mathrm{SE}$. This was followed by a steadily decreasing number during successive 20-day intervals. After 100 days, RAs had only 1.30 branches/ axon \pm 0.14 . However, the proportion of branches regenerating at least as far as the center of the scar remained relatively constant after the first 39 days (Fig. $4 E$ ). There was no significant correlation between distance of meas- 

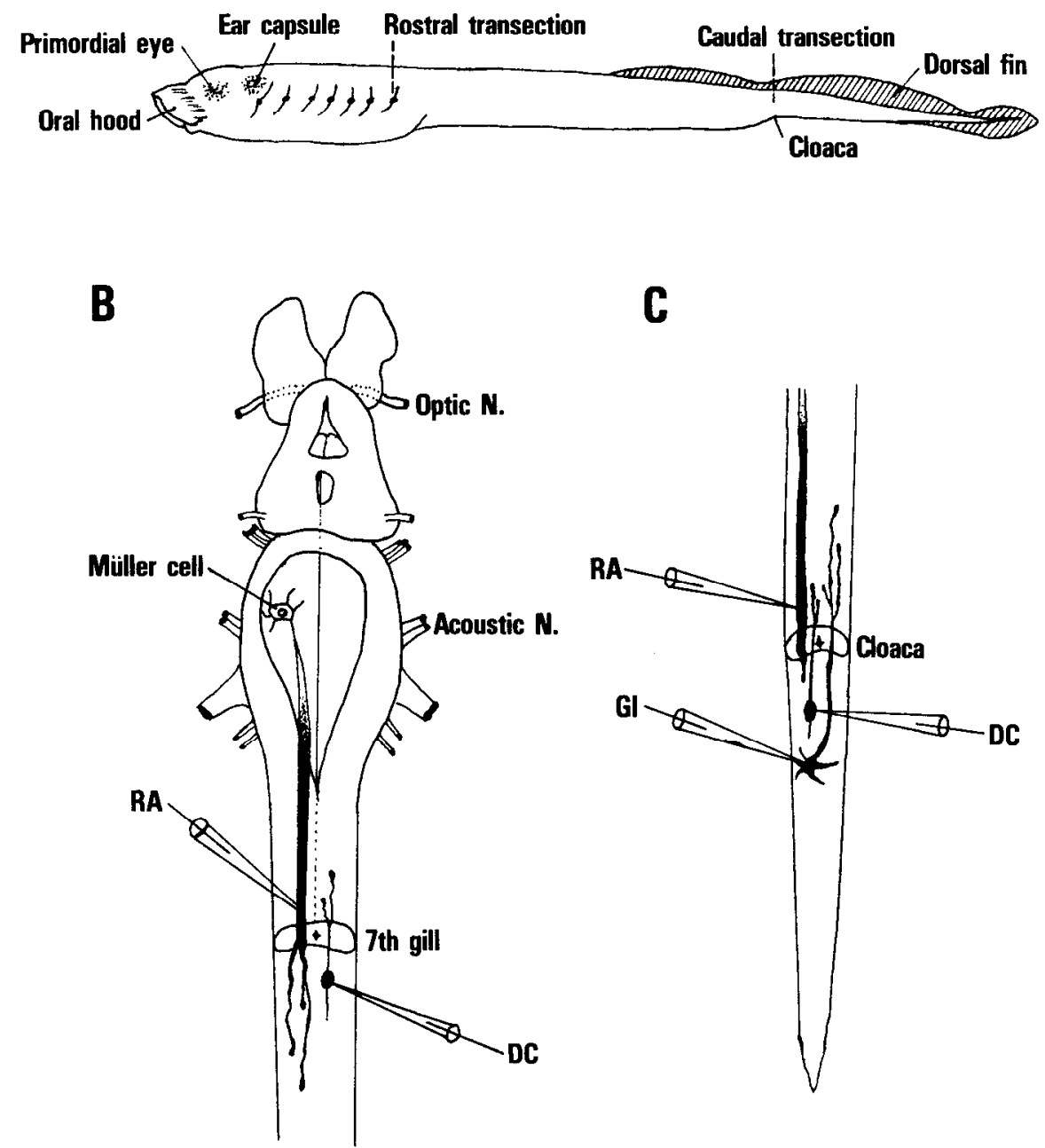

Figure 1. The experimental arrangement. $A$, Semischematic lateral view of larval sea lamprey showing the two levels of spinal cord transection. $B$, In rostrally transected spinal cords, RAs were directly injected with HRP within $2.5 \mathrm{~mm}$ above the scar. DCs located just below the scar were injected intrasomatically. $C$, In caudally transected spinal cords, RAs were directly injected just above the scar, and DCs and GIs located just below the scar were injected intrasomatically. The spinal cord length is scaled down greatly compared to the width.

ured regeneration and the diameter of the parent axon, which ranged from 4 to $27 \mu$.

Regeneration of identified RAs. RAs located dorsolateral to the gray matter and having diameters in the rostral cord greater than $20 \mu$ were assumed to be Mauthner axons (Fig. 2A). 'I'wo such axons were injected in rostrally transected animals at 49 and 62 days of recovery. These had a total of 10 branches, five of which regenerated up to or past the transection. The distance of branch regeneration ranged from $-274 \mu$ to $+1020 \mu$. A Mauthner axon injected 12 days after transection had retracted $1744 \mu$ and did not branch. Several other large axons injected in the dorsolateral column were probably Mauthner axons, even though their diameters were slightly smaller than $20 \mu$. They showed similar branching and regeneration properties as other RAs including Mauthner axons.

One axon of the second isthmic giant reticulospinal neuron (I2) was identified by its characteristic location in the ventrolateral part of the ventral column and its characteristic bursting behavior on cord stimulation (Rovainen, 1967a). Its diameter was $8.8 \mu$. It had two branches which, at 81 days post-transection, had regenerated to positions of $+2676 \mu$ and $0 \mu$ relative to the center of the scar.

Caudal transections. In contrast to RAs transected proximally (i.e., within $2 \mathrm{~cm}$ of their cell bodies), those transected distally showed little regenerative capacity in terms of both distance (Figs. $3 B$ and $4 B$ ) and numbers of branches/axon (Fig. $4 D$ ). Only 3 of 28 branches in 20 axons injected more than 39 days post-transection had regenerated to the scar, and only one had grown $38 \mu$ beyond the transection. It may be that more regeneration would be seen at longer recovery times. The regression of distance of regeneration on recovery time predicted that the average neurite of caudally transected RAs 

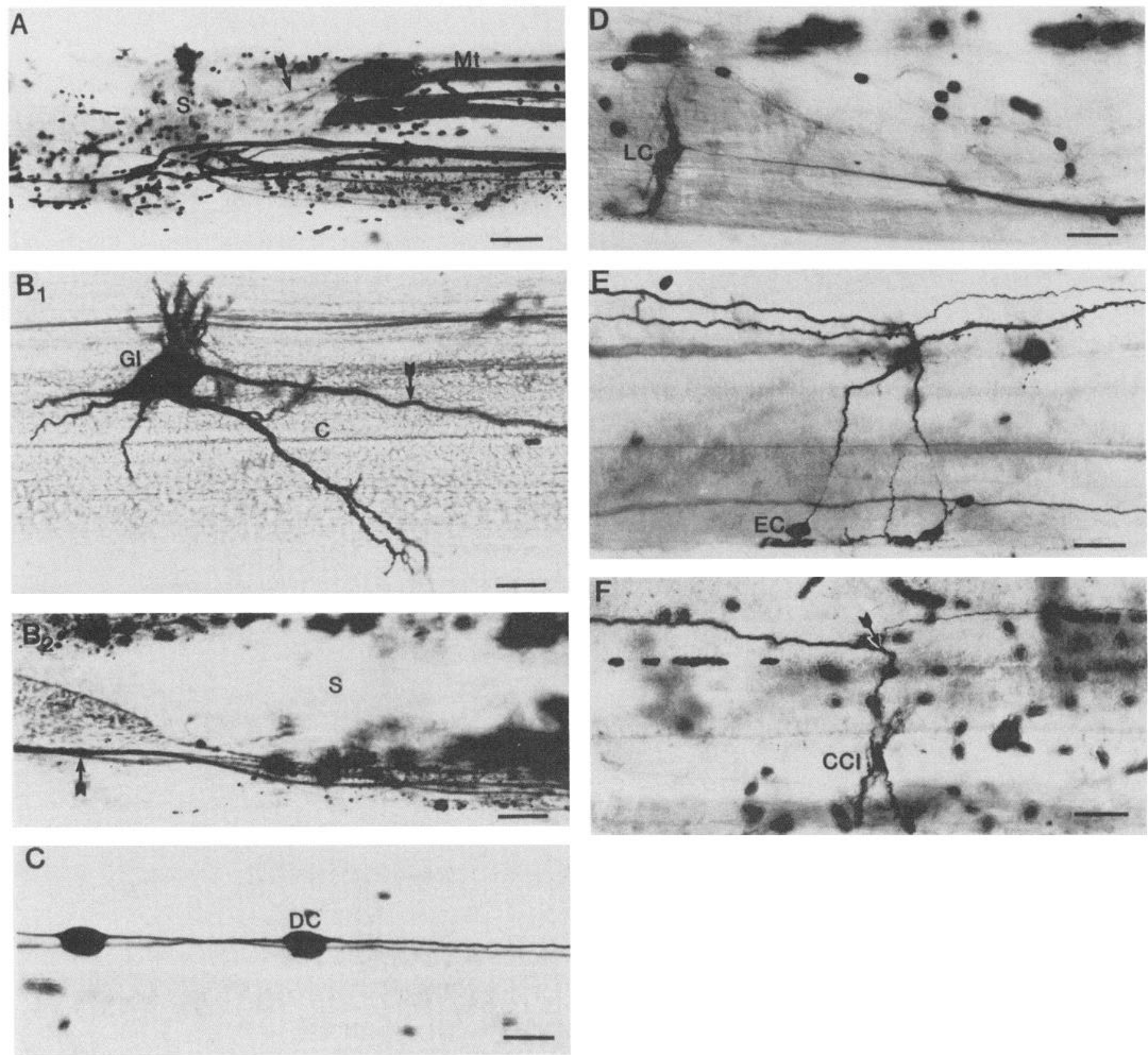

Figure 2. HRP-injected regenerating axons and neurons in spinal cord whole mounts. Caudal is left in all micrographs except D. A, Regenerating reticulospinal axons in an animal 62 days after a rostral transection. The entire width of the cord is seen. Note the pronounced terminal enlargement of the Mauthner axon $(M t)$ with fine filopodia extending posteriorly from it (arrow). Note also that two of the axons loop backward, and three axon branches have regenerated past the center of the scar $(S)$. $B_{1}$, Giant interneuron $(G I)$ located $2.5 \mathrm{~mm}$ below a caudal transection 85 days postoperatively. Note the anteriorly projecting axon (arrow) as it sweeps toward the contralateral side. $C$, central canal. An injected unidentified small axon is seen passing among the lateral dendrites. $B_{2}$, Axon of GI in $B_{1}$ as it branches (arrow) and regenerates past the center of the scar $(S)$. $C$, The dorsal cells $(D C)$ located $4.5 \mathrm{~mm}$ below a rostral transection in an animal 49 days postoperatively. $D$, Lateral cell $(L C)$ located $6.8 \mathrm{~mm}$ above the scar in an animal 12 days post-transection. Note axon projecting posteriorly and ipsilaterally. $E$, Two edge cells $(E C)$ located 2 $\mathrm{mm}$ above the scar in an animal 120 days post-transection. Note that both cells have decussating axons which bifurcate on the other side of the central canal and send one anterior and one posterior projection. $F$, Crossed caudally projecting interneuron $(C C I)$ located $4 \mathrm{~mm}$ above the scar in an animal 96 days post-transection. Note the contralateral axonal bifurcation (arrow) with a main posterior projection and a fine anteriorly projecting branch. Calibration bars: $A, 125 \mu ; B$ to $F, 50 \mu$.

would reach the scar after 202 days, although the correlation did not reach significance at the 0.05 level (Fig. $3 B$ ). Once again, no significant correlation was observed between distance of regeneration and parent axon diameter, which ranged from 4 to $14 \mu$.

\section{Anteriorly projecting axons}

Giant interneurons. GIs are large, second-order sensory cells whose axons decussate and project, mostly unbranched, to the brain (Rovainen, 1967b, 1974; Tang 

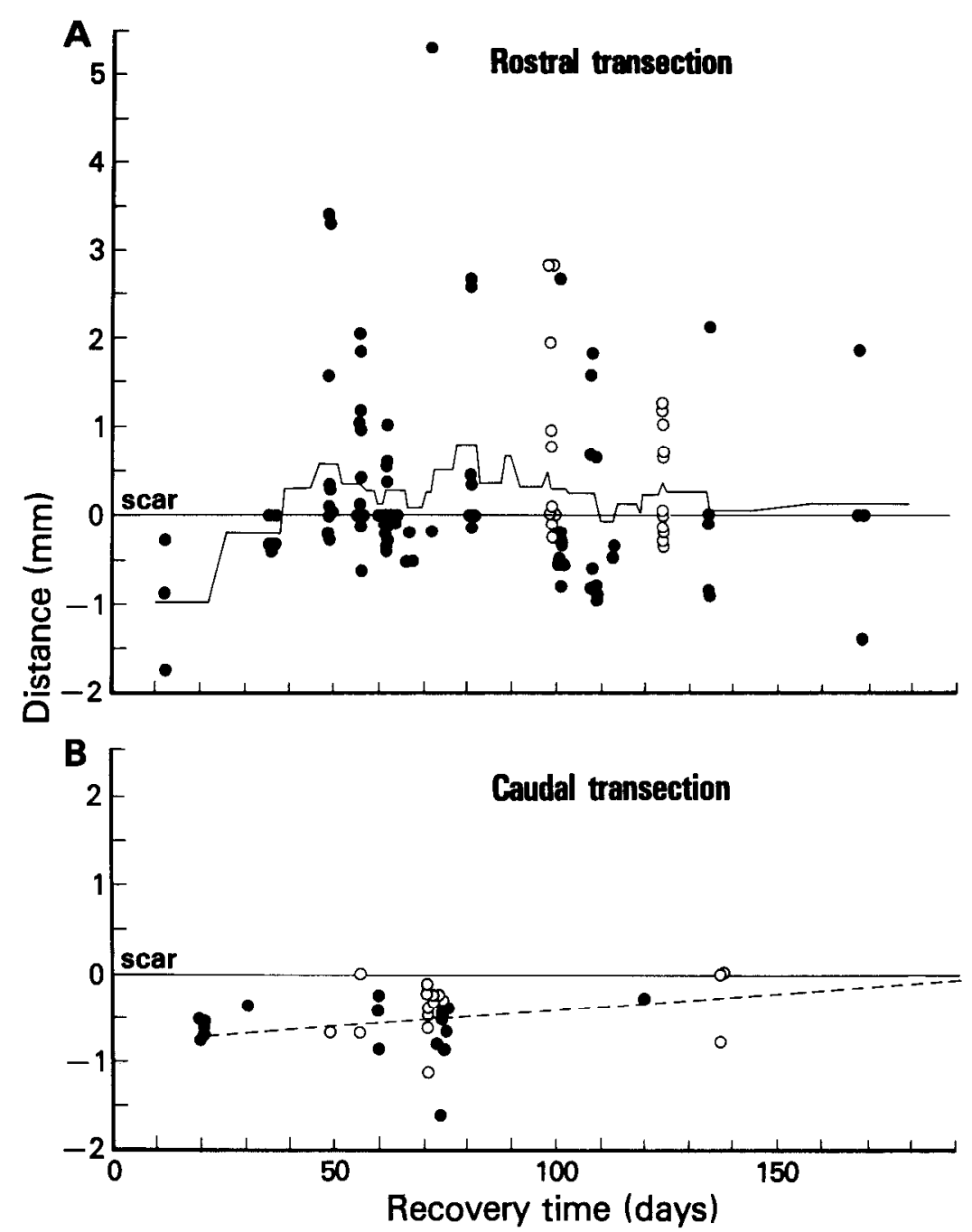

Figure 3. Time course of regeneration of RAs. The caudalmost extent of HRP-stained profile is plotted for each axon branch. The location of the center of the scar is represented as 0 . Negative axon tip locations imply axon retraction, and positive values imply regeneration beyond the scar. $A$, Rostral transections. The fine line plot is a running mean of axon tip locations for all axon branches within \pm 10 days of the indicated time, with means recalculated at 1 -day increments. $B$, Caudal transections. The dashed line is a linear regression plot. The slope is $3.8 \mu /$ day $(r=0.32,0.1$ $>p>0.05$ ). Solid circles, postoperative recovery at $23^{\circ} \mathrm{C}$. Open circles, recovery at $16^{\circ} \mathrm{C}$.

and Selzer, 1979). They are located in the caudal half of the spinal cord. Thirteen GIs were injected with HRP within $3.5 \mathrm{~mm}$ below a scar (mean was $2.14 \mathrm{~mm} \pm 0.13$ $\mathrm{SE}$ ) in caudally transected animals (Fig. $2 B_{1}$ ). The time course of regeneration is shown in Figure $5 A$. During the first 45 days, five axon tips were located an average of $641 \mu \pm 144 \mathrm{SE}$ proximal to the center of the scar. Only one axon branched. Thereafter, seven axons had a total of 11 branches, which regenerated an average of $+488 \mu$ $\pm 173 \mathrm{SE}$ beyond the scar (Fig. $2 B_{2}$ ). The furthest observed was $1.3 \mathrm{~mm}$ beyond the scar. All branches remained in their normal position contralateral to the cell body, but three branches looped backward (Table II). In 15 control HRP-injected GIs, the mean distance of axon staining was $2739 \mu \pm 560 \mathrm{SE}$. The longest distance was $7150 \mu$.
Dorsal cells. DCs are primary sensory neurons located just below the dorsal columns through the length of the spinal cord. Their axons project in the ipsilateral dorsal column to the brain (Rovainen, 1967b; Tang and Selzer, 1979). Twenty-two DCs were stained with HRP within $2.5 \mathrm{~mm}$ of the scar (mean was $1.15 \mathrm{~mm} \pm 0.13 \mathrm{SE}$ ) from 20 to 175 days post-transection (Fig. $2 C$ ). Some axons began to grow beyond the scar by 36 days (Fig. $5 B$ ). After this time, $53 \%$ of the axons (59\% of branches) regenerated at least to the center of the scar (Table I), although the measured distances of regeneration were small $(-77 \mu \pm 97 \mathrm{SE})$ in comparison with axons of RAs and GIs. The furthest observed was $1.1 \mathrm{~mm}$. Once again, regenerating axons tended to grow only rostrally and to remain ipsilateral to their original positions (Table II). Regenerating DC neurites were very thin and tortuous. 

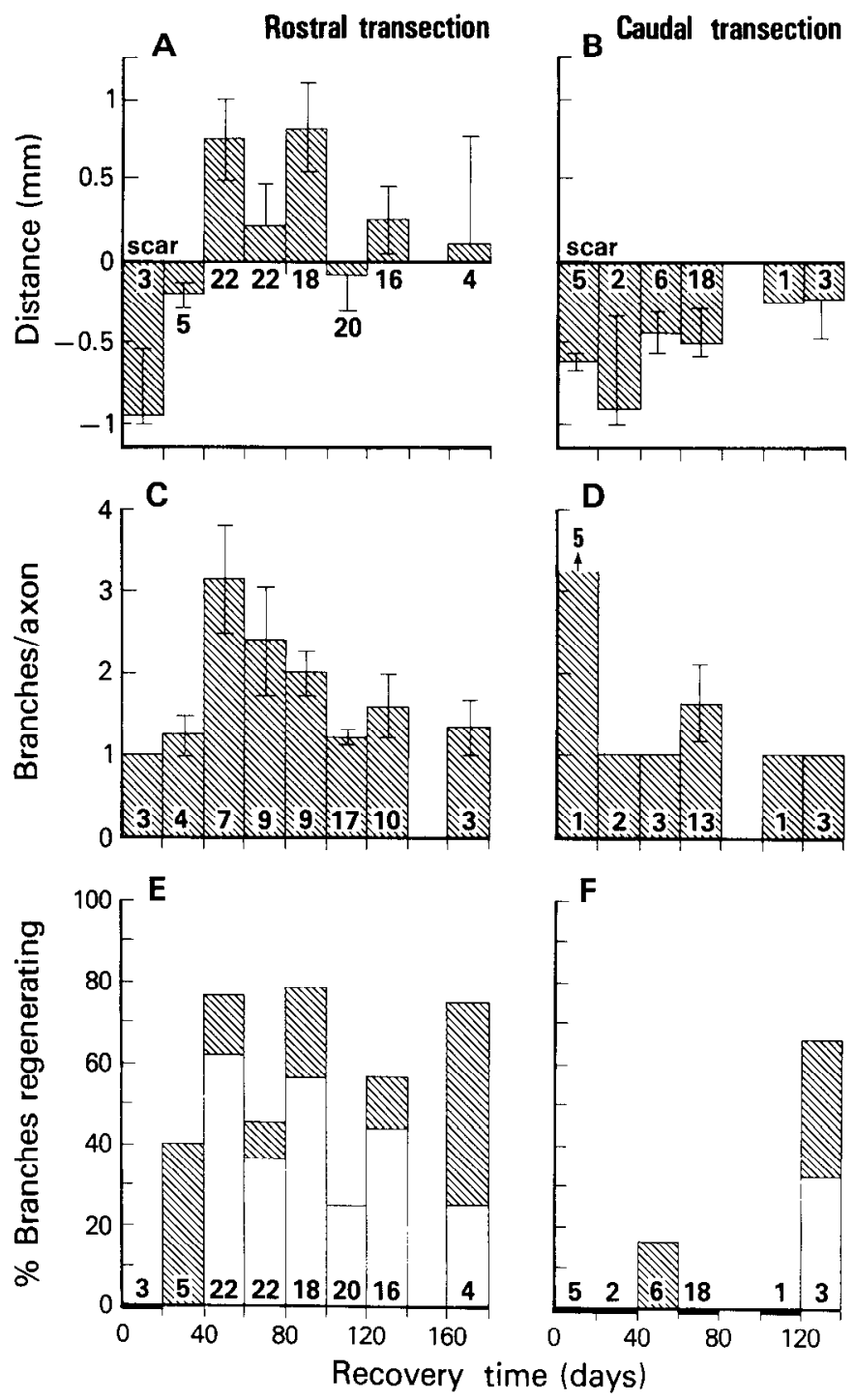

Figure 4. Time courses of parameters of regeneration in proximally versus distally transected RAs. $A$, Mean distances of branch regeneration +SE for proximally transected RAs at 20 -day postoperative intervals. $B$, Same for distally transected RAs. $C$, Number of branches per axon $+\mathrm{SE}$ for proximally transected RAs. $D$, Same for distally transected RAs. $E$, Percentages of branches of proximally transected RAs regenerating past the center of the scar (open bars) or up to the center of the scar (hatched bars). $F$, Same for distally transected RAs. Numerals indicate numbers of axon branches studied for $A, B$, $E$, and $F$ and numbers of axons studied for $C$ and $D$.

They did not photograph well but were easily followed by focusing up and down on the whole mount.

As with RAs, regeneration was not correlated to parent axon diameter. However, it was observed that 40 axotomized DCs had somewhat larger parent axon diameters $(1.77 \mu \pm 0.14 \mathrm{SE})$ than 15 untransected controls $(1.29 \mu$ $\pm 0.12 \mathrm{SE}$ ). In a previous study (Yin et al., 1981), we were surprised to find that the proximal axons of axotomized DCs had faster conduction velocities than controls $(0.66$ $\mathrm{m} / \mathrm{sec}$ at 6 weeks versus $0.51 \mathrm{~m} / \mathrm{sec}$ for controls). Our present findings of an increase in axon diameter for axotomized DCs might partially explain the earlier physiological findings.

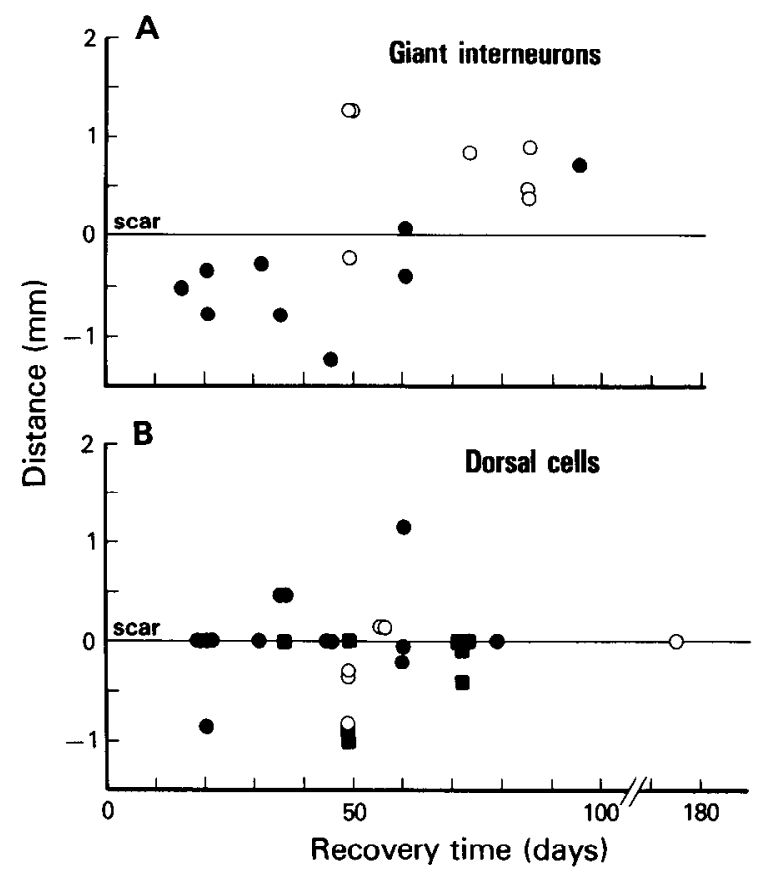

Figure 5. Time course of axonal regeneration for rostrally projecting neurons. $A$, GIs all in caudally transected animals. $B$, DCs. Open and solid circles indicate recovery at $16^{\circ} \mathrm{C}$ and $23^{\circ} \mathrm{C}$ in caudally transected animals. Squares indicate recovery from rostral transections at $23^{\circ} \mathrm{C}$.

Axons of DCs regenerated as well or better across a caudal transection as compared to a rostral one. Eight axons (none branched) of DCs in the rostral cord more than 36 days post-transection had reached an average location of $-288 \mu \pm 149 \mathrm{SE}$ (i.e., $288 \mu$ caudal to the center of the scar). Four axons just reached the scar, and none regenerated past it. Fourteen branches of nine DC axons in the caudal spinal cord regenerated $+43 \mu \pm 119$ SE past a caudal transection. Four of these axons regenerated to the center of the scar, and five others passed it. In 17 control HRP-injected DCs, mean distance of axon staining was $2490 \mu \pm 241 \mu \mathrm{SE}$. The longest distance was $4500 \mu$.

\section{Other identified neurons}

In the course of these experiments, several other identified neurons were serendipitously injected with HRP. Although these types of cells were not studied systematically, the data are worth recording because they document the ability of the axons of previously identified types of neurons to regenerate. These neurons are much more difficult to impale in larvae than in adults. Thus, individual observations are of value. The specific conditions and distances of regeneration are listed in Table III.

Lateral cells (Fig. 2D). Lateral cells (LCs) are large, posteriorly projecting interneurons located in the lateral margin of the grey column of the rostral half of the spinal cord (Rovainen, 1974; Tang and Selzer, 1979). Their axons course unbranched in the ipsilateral lateral column (Tang and Selzer, 1979). Two LCs injected 12 days posttransection had not regenerated. This is similar to what was observed for RAs, DCs and GIs. One LC injected 96 days post-transection regenerated into the scar, looped back $180^{\circ}$, and grew anteriorly for about $3.4 \mathrm{~mm}$, giving 
TABLE III

Regeneration of individual identified neurons

\begin{tabular}{|c|c|c|c|c|c|c|}
\hline Cell type & Recovery & Temperature & $\begin{array}{l}\text { Transection } \\
\text { Location }\end{array}$ & Cell Location $^{a}$ & Axon Tip Location ${ }^{b}$ & Tip Morphology \\
\hline & days & ${ }^{\circ} \mathrm{C}$ & & $\mu$ & $\mu$ & \\
\hline $\mathrm{LC}$ & 12 & 23 & Rostral & 4360 rostral & -106 IPSI & Tapered \\
\hline $\mathrm{LC}$ & 12 & 23 & Rostral & 6778 rostral & -812 IPSI & Tapered \\
\hline \multirow[t]{5}{*}{$\mathrm{LC}$} & 135 & 23 & Rostral & 5154 rostral & -64 IPSI & Loop \\
\hline & & & & & $\begin{array}{c}-3452 \text { IPSI } \\
\text { branches }\end{array}$ & Blunt \\
\hline & & & & & -1228 IPSI & Tapered \\
\hline & & & & & -904 IPSI & Tapered \\
\hline & & & & & -2287 IPSI & Tapered \\
\hline EC & 71 & 16 & Caudal & 974 rostral & - 162 IPSI & Swollen \\
\hline $\mathrm{EC}$ & 120 & 16 & Caudal & 1949 rostral & -1553 IPSI & Tapered \\
\hline $\mathrm{EC}$ & 120 & 16 & Caudal & 2083 rostral & +212 IPSI & Tapered \\
\hline CCI & 71 & 23 & Rostral & 1017 caudal & -42 IPSI & Swollen \\
\hline CCI & 76 & 23 & Rostral & 3940 rostral & +584 IPSI & Tapered \\
\hline $\mathrm{CCI}$ & 96 & 23 & Caudal & 4165 rostral & +954 IPSI & Tapered \\
\hline
\end{tabular}

${ }^{a}$ Relative to the center of the transection scar.

${ }^{b}$ Distance relative to the center of the transection scar; side relative to the parent axon, which in the CCs and ECs was contralateral to the cell body. IPSI, ipsilateral.

off three fine branches. The main branch appeared to terminate at the ipsilateral edge of the spinal cord.

Edge cells (Fig. 2E). Edge cells (ECs) are interneurons located in the lateral white matter, mostly near the edge of the spinal cord. The major projection, in most cases, is anterior, either ipsilateral or contralateral (Rovainen, 1974; Tang and Selzer, 1979). Some ECs project posteriorly or both anteriorly and posteriorly (Tang and Selzer, 1979). Two edge cells located above a caudal transection were injected 120 days post-transection. Both had decussating axons which gave off an anterior and a posterior process. One posterior axon branch regenerated past the scar, and the other could not be followed as far as the scar. Because most ECs do not normally project posteriorly for long distances (Rovainen, 1974; Tang and Selzer, 1979), the failure of one axon to reach the scar may simply mean that it had not been cut. A third EC above a caudal transection was injected 71 days postoperatively. It too had a decussating axon with one anterior and one posterior projection. The posterior branch ended in a terminal enlargement $162 \mu$ proximal to the center of the scar.

Crossed caudally projecting interneurons (Fig. 2F). Three injected neurons fit the description given by Buchanan (1982) of the crossed caudally projecting interneurons (CCIs) which are rhythmically activated during fictive swimming and, therefore, may be involved in swimming pattern generation. They were studied 71,76 , and 96 days after transection. All three had bifurcating axons with a large posterior branch and a more slender anterior branch. In one, the anterior branch was transected and regenerated back to the scar. In the other two, the cut posterior branch regenerated beyond the scar.

\section{Discussion}

Distance of axonal regeneration. The present studies confirm the limited degree of regeneration of RAs described previously in this laboratory on the basis of serial section reconstructions in unlabeled preparations (Selzer,
1978). In our previous report, the maximum distance of regeneration in 29 branches of 18 RAs in an animal 17 weeks post-transection was $3.5 \mathrm{~mm}$ beyond the center of the scar. The longest distance of neurite regeneration observed in the present study was $5.3 \mathrm{~mm}$. In the previous study, $62 \%$ of branches or $67 \%$ of axons regenerated at least as far as the transection site, as compared with $57 \%$ and $55 \%$, respectively, in the present report. Rovainen (1976) suggested that RAs of smaller larvae can grow at least $1 \mathrm{~mm}$ but less than $10 \mathrm{~mm}$ beyond a transection, whereas Wood and Cohen (1979) stated that their longest HRP-labeled neurite extended $3.1 \mathrm{~mm}$ caudal to a transection.

An intriguing recent report by Forehand and Farel (1982) suggests that bullfrog tadpoles show only limited behavioral recovery and only short distance regeneration of long axon tracts following midthoracic spinal transections. However, if the lesioned animals are allowed to survive past metamorphosis, there is further regeneration so that brainstem neurons which normally projected to the lumbar region re-establish such projections. No evidence was found for regeneration of rostral projections from spinal cord. If these findings are correct, this would be the first evidence for long distance regeneration in a vertebrate spinal cord preparation. It is not known whether a similar phenomenon occurs with transformation of lampreys from larval to adult forms.

Direction of neurite growth. Despite the limited distance of regeneration, the axons we have studied showed a marked tendency to grow back toward the transection scar. The mechanism of this specificity is not clear. Evidence to be presented in a future report suggests that a simple polarity of neurons, such that axonal growth always proceeds away from the riil body, is not an adequate explanation. It is tempting to speculate that the scar may elaborate a trophic substance and that there is a gradient of decreasing activity of this substance away from the scar. This would explain not only the directional specificity of regeneration but also the limited distance of growth distal to the scar. However, such a 
mechanism would not explain the tendency of regenerating fibers in the distal segment to assume positions on the same side of the midline as their original paths.

Not all fibers continued to grow in their original direction. Eleven percent of regenerating branches $(21 \%$ of axons) looped back. This was invariably in the region before the scar. Only $5 \%$ of branches crossed the midline. These results are consistent with the results of Selzer (1978) in serial thick sections without HRP injection. The phenomena of looping back and of deviation of regenerating axon branches away from their accustomed locations has also been described by Rovainen (1976) in uninjected serial sections and by Wood and Cohen (1981) in HRP-injected preparations.

Time course of regeneration in relation to behavioral recovery. In the previous report (Selzer, 1978), behavioral observations suggested recovery of ascending sensory projections. The present results provide a basis for those behavioral studies by demonstrating that axons of DCs, which are primary sensory cells, and GIs, which are second-order sensory neurons, can regenerate anteriorly.

The time course of regeneration of axons matches fairly closely the time course of behavioral recovery noted previously (Selzer, 1978). At $23^{\circ} \mathrm{C}$, evidence for recovery of ascending sensory projections appeared at about 2.5 to 3 weeks. In the present study, some dorsal cell axons could be traced as far as the center of the scar by 20 days. In the behavioral studies, evidence for some descending connections occurred by 4 weeks, while coordinated swimming did not occur until 6 to 7 weeks. In the present study, RAs could be traced to the center of the scar as early as 5 weeks and reached maximum distance by 7 to 10 weeks. We may assume that a few fibers would already have regenerated by the time we were able to demonstrate regeneration in our limited sample of injected cells. However, the very close timing of behavioral recovery and neurite regeneration suggests that functional connections are formed soon after neurite regeneration. 'The mean distance of regeneration for proximally transected RAs between 40 and 100 days postoperatively was only $574 \mu$. For GIs and DCs, the means were still lower. However, these means include fibers which ended rostral to the scar and had presumably not regenerated. It is not clear what significance should be placed on such a figure when relating axonal regeneration to behavioral recovery. It may be that recovery is more dependent on the percentages of fibers regenerating or on the distance, timing, and selectivity of synaptic connections of a few key regenerating axons.

Retraction of regenerated neurites. In any study of the regenerative capacities of axons, the question must always arise as to whether sufficient time was allowed to achieve maximum regeneration. The present study suggests that RAs do not continue to regenerate indefinitely. Instead maximum degrees of axon branching and maximum distances of neurite elongation were observed between 40 and 100 days in rostrally transected animals. Thereafter, both measures of regeneration decreased, suggesting a process of neurite retraction. The data for the other axon types are not sufficient to draw similar conclusions.

Differences in axonal regeneration among neurons types. The percentages of axons regenerating as far as or beyond the transection were similar for all three types of neurons studied (Table I). However, DC axons were followed for much shorter distances than those of RAs or GIs. It is possible that this is because, as suggested by control-injected cells, HRP does not penetrate as far in smaller axons, or at least that small HRP-labeled axons are less visible in whole mounts than larger ones. The larger percentage of fading neurite profiles observed in DCs compared with RAs is consistent with this notion. However, the measured distances of DC axon regeneration were well within the HRP staining range. Therefore, the difference may represent a differential regenerative ability between DCs and the other two cell types. In support of the latter is the lack of correlation between parent axon diameter and distance of regeneration observed in RAs and DCs.

Relation of axonal regeneration to location of the lesion. The most intriguing finding of the present study is the relatively poor regenerative capacities of RAs transected distally as compared with those transected proximally. It is unlikely that this represents a difference in the environments of the rostral and caudal regions of the spinal cord as matrices for axonal regeneration. GIs whose cell bodies were located below a caudal transection regenerated as well as did proximally transected RAs, Moreover, DCs located just below a caudal transection regenerated at least as well as those in the rostral cord. Observations on small caudally projecting axons impaled accidentally just above a caudal transection showed that the axons could regenerate for relatively long distances beyond the scar. Such axons are presumably not RAs, and their cell bodies could well be located in the spinal cord close to the transection.

The explanation for the differences in regeneration between proximally and distally transected RAs is most likely related to intraneuronal factors. Thus, we propose that central axons may regenerate better the closer the transection is to their cell bodies. The present experiments were not designed to test this hypothesis, inasmuch as only two levels of cord transection were studied. Most of our experiments were performed with the rostral transection because this lesion produces a more obvious behavioral deficit. The caudal transections were added in order to allow study of GIs, which are absent from the rostral cord. However, interpolation of data from the study of Borgens et al. (1981) with our own results supports this hypothesis. They transected spinal cords of large larval sea lampreys at a point about midway between the head and the end of the tail. This is about halfway between the two lesions we made. Although they did not quantify distance of regeneration, they stated that $53 \%$ of RAs injected with Lucifer Yellow terminated proximal to a transection at 44 to 63 days. In our study, the equivalent figures for proximally and distally transected axons during this time window were $18 \%$ and $83 \%$, respectively. For all axons beyond $\mathbf{4 0}$ days, our figures were $45 \%$ and $85 \%$, respectively.

In goldfish, Bernstein and Gelderd (1970) reported that 60 days after spinal cord transection the descending long axon tracts contained 35 to $49 \%$ of their normal complement of fibers $2 \mathrm{~cm}$ caudal to the transection. This 
suggests a somewhat greater maximum distance of regeneration for goldfish spinal axons compared with those of lamprey. However, it cannot be concluded from these data that axons of goldfish spinal cord transected far from their cell bodies can regenerate for long distances. In the goldfish study, regeneration was assessed by retransection one segement higher and counting degenerating fibers $2 \mathrm{~cm}$ below the first transection. Thus, the origins of the axons in the reconstituted long axon tract cannot be determined. It may be that they originated from neurons only one segment above the transection.

Studies on peripheral nerve have differed with regard to whether a relationship exists between rate of regeneration and distance of injury from cell body. Clinical observations on human nerve injuries have suggested an inverse relationship, although the evidence for this was indirect (see Sunderland, 1978; Selzer, 1980 for reviews).

Relevance to mammalian spinal cord regeneration. The characteristics of lamprey spinal cord regeneration reported here are likely to be of relevance to the problem of regeneration in mammalian spinal cord. David and Aguayo (1981) have shown that axons of spinal neurons can grow into peripheral nerve bridges for $3 \mathrm{~cm}$ and then enter the medulla. Similarly, neurons of the medulla grow into the spinal cord. However, upon entering the central nervous system, the fibers grow no more than 2 $\mathrm{mm}$. This is strikingly similar to the finding of limited axonal regeneration in the lamprey. Moreover, the cells of origin in these bridges were located within 4 to $6.5 \mathrm{~mm}$ of the proximal stump of the bridge. Once again, this correlates well with our tentative conclusion that spinal axons transected close to their cell bodies regenerate more readily than those cut distally. The possible application of this principal to mammalian spinal cord is further illustrated by the experiments of Aguayo and colleagues in which $1.5-\mathrm{cm}$ lengths of rat thoracic spinal cords were removed and autologous sciatic nerve grafts inserted between the cut ends (Richardson et al., 1982). The origins of fibers growing into the graft were studied by tracer methods. The cells of origin were either local spinal neurons near the level of the graft insertion or dorsal root ganglion cells at the same level or up to seven segments distally. Although fibers were sent into the proximal stumps of the graft, no evidence was found to suggest that these fibers re-enter the cord distally. Corticospinal tract axons did not grow into the graft at all.

The emphasis of the work on peripheral nerve grafts into CNS has been on the importance of extraneuronal factors in limiting axonal regeneration. The present findings suggest that factors intrinsic to the neuron are also critical in limiting the likelihood and the distance of axonal regeneration. A more definitive test of the relationship of regenerative capacity to distance of axotomy from the cell body will require making a series of transections at varying locations along the length of the lamprey spinal cord and observing the regenerative behavior of the giant reticulospinal axons.

\section{References}

Bernstein, J. J., and J. B. Gelderd (1970) Regeneration of the long spinal tracts in the goldfish. Brain Res. 20: 33-38.

Borgens, R. B., E. Roederer, and M. J. Cohen (1981) Enhanced spinal cord regeneration in lamprey by applied electric fields. Science 213: 611-617.

Buchanan, J. T. (1982) Identification of interneurons with contralateral, caudal axons in the lamprey spinal cord: Synaptic interactions and morphology. J. Neurophysiol. 47: 961975.

David, S., and A. J. Aguayo (1981) Axonal elongation into peripheral nervous system "bridges" after central nervous system injury in adult rats. Science 214: 931-933.

Forehand, C. J., and P. B. Farel (1982) Anatomical and behavioral recovery from the effects of spinal cord transection: Dependence on metamorphosis in anuran larvae. J. Neurosci. 2: 654-662.

Hibbard, E. (1963) Regeneration in the severed spinal cord of chordate larvae of Petromyzon marinus. Exp. Neurol. 7: 175185.

Richardson, P. M., U. M. McGuinness, and A. J. Aguayo (1982) Peripheral nerve autographs to the rat spinal cord: Studies with axonal tracing methods. Brain Res. 237: 147-162.

Rovainen, C. M. (1967a) Physiological and anatomical studies on large neurons of central nervous system of the sea lamprey (Petromyzon marinus). I. Müller and Mauthner cells. J. Neurophysiol. 30: 1000-1023.

Rovainen, C. M. (1967b) Physiological and anatomical studies on large neurons of central nervous system of the sea lamprey (Petromyzon marinus). II. Dorsal cells and giant interneurons. J. Neurophysiol. 30: 1024-1042.

Rovainen, C. M. (1974) Synaptic interactions of identified nerve cells in the spinal cord of the sea lamprey. J. Comp. Neurol. 154: 189-206.

Rovainen, C. M. (1976) Regeneration of Müller and Mauthner axons after spinal transection in larval lampreys. J. Comp. Neurol. 168: 545-554.

Selzer, M. E. (1978) Mechanisms of functional recovery and regeneration after spinal cord transection in larval sea lamprey. J. Physiol. (Lond.) 277: 395-408.

Selzer, M. E. (1980) Regeneration of peripheral nerve. In The Physiology of Peripheral Nerve Disease, pp. 358-431, W. B. Saunders, Philadelphia.

Sunderland, S. (1978) Nerves and nerve injuries, Ed. 2, Churchill Livingstone, London.

Tang, D., and M. E. Selzer (1979) Projections of lamprey spinal neurons determined by the retrograde axonal transport of horseradish peroxidase. J. Comp. Neurol. 188: 629-646.

Wood, M. R., and M. J. Cohen (1979) Synaptic regeneration in identified neurons of the lamprey spinal cord. Science 206: 344-347.

Wood, M. R., and M. J. Cohen (1981) Synaptic regeneration and glial reactions in the transected spinal cord of the lamprey. J. Neurocytol. 10: 57-79.

Yin, H. S., K. K. Wellerstein, and M. E. Selzer (1981) Effects of axotomy on lamprey spinal neurons. Exp. Neurol. 73: 750761 . 